\title{
Characteristics of upper urinary tract urothelial carcinoma in the context of bladder cancer: a narrative review
}

\author{
Nicola Giudici ${ }^{1}$, Fieke Bonne ${ }^{1}$, Jennifer Blarer ${ }^{2}$, Martina Minoli ${ }^{1}$, Friedemann Krentel ${ }^{1}$, Roland Seiler ${ }^{1} \wedge$ \\ ${ }^{1}$ Department of Urology, Inselspital, Bern University Hospital, University of Bern, Bern, Switzerland; ${ }^{2}$ Department of Urology, Hospital Center \\ Biel/Bienne, Biel/Bienne, Switzerland \\ Contributions: (I) Conception and design: N Giudici, R Seiler; (II) Administrative support: R Seiler; (III) Provision of study materials or patients: N \\ Giudici, F Bonne, R Seiler; (IV) Collection and assembly of data: N Giudici, F Bonne, R Seiler; (V) Data analysis and interpretation: N Giudici, F \\ Bonne, R Seiler; (VI) Manuscript writing: All authors; (VII) Final approval of manuscript: All authors. \\ Correspondence to: Roland Seiler. Department of Urology, University of Bern, Bern 3010, Switzerland. Email: r_seiler@gmx.ch, roland.seiler@insel.ch.
}

\begin{abstract}
Urothelial carcinomas (UC) arise from the urothelium that covers the proximal urethra, urinary bladder, and the upper urinary tract. In daily routine and clinical trials UC originating from different locations are often treated and investigated in the same manner. However, differences between the two locations seem to be apparent and may question in handling them as a single oncologic entity. In this review we discuss similarities and differences between bladder and upper urinary tract UC and consider their potential impact on treatment strategies. Despite similarities of UC in the bladder (BC) and the upper urinary tract (UTUC), clinicopathologic and molecular differences may question to generally assemble both as a single tumor entity. Treatment standards for UTUC are often adopted from BC. However, a specific investigation in the former may still be meaningful as shown by the example of adjuvant cisplatin based chemotherapy. In conclusion, future investigations should prioritize the understanding of the tumor biology of both BC and UTUC. This may reveal which UTUC can be treated according to treatment standards of $\mathrm{BC}$ and in which cases, a separate approach may be more appropriate.
\end{abstract}

Keywords: Urothelial carcinomas (UC); bladder cancer; upper urinary tract

Submitted Dec 02, 2020. Accepted for publication Apr 08, 2021.

doi: $10.21037 /$ tau-20-1472

View this article at: http://dx.doi.org/10.21037/tau-20-1472

\section{Introduction}

Urothelial carcinomas (UC) are the 7 th most common cancers and can be located anywhere where a body surface covered with urothelium is present. In the clinical practice UC are historically divided in three groups: UC of the bladder (BC), upper urinary tract UC (UTUC) and urethral carcinoma. BC accounts for $90-95 \%$ of UC $(1,2)$. UTUC, defined as a malignancy arising from urothelial cells in the ureter and/or pyelocaliceal cavities, accounts for $5-10 \%$ of all UC. Primary urethral carcinoma is rare and accounts for
$<1 \%$ of all genitourinary malignancies (3).

$\mathrm{UC}$ of the bladder and the upper urinary tract share histomorphological similarities. However, differences between both may still be relevant. Embryologically, the urinary bladder and the upper urinary tract arise from two different germ cell layers. Both are exposed to carcinogens and toxins excreted in urine. However due to their function, their exposure is different. The bladder stores the urine and its urothel is subsequently exposed for a longer period, while the upper tract transports the urine and is only exposed for a short term $(4,5)$. Differences can also be observed at

$\wedge$ ORCID: 0000-0002-3529-2088. 
initial staging. While $75-85 \%$ of patients present with noninvasive BC, only a third of patients with UTUC have noninvasive disease (6).

Based on similarities between both, current diagnostic and therapeutic strategies overlap. Moreover, in clinical practice metastatic $\mathrm{UC}$ are considered and treated as a single oncologic entity, regardless of the primary tumor location. Also in clinical trial settings both are often included in similar or even in the same trial. This may be in contrast to findings from molecular investigations that revealed similarities but also differences between BC and UTUC.

In this review, we aim to perform a comparison between BC and UTUC with regard to clinical, pathological, molecular and therapeutic characteristics.

We present the following article in accordance with the Narrative Review reporting checklist (available at http:// dx.doi.org/10.21037/tau-20-1472).

\section{Methods}

The authors have acquired the evidence for the narrative review in articles indexed online in the MEDLINE literature database through PubMed (http://ncbi.nlm.nih. gov/pubmed) between April 2020 and October 2020.

\section{Clinical characteristics (Table 1)}

\section{Gender}

Men are three times more likely to develop BC than women (2) and are more frequently diagnosed with nonmuscle invasive $\mathrm{BC}$, whereas women present more advanced tumor stages and worse prognosis when compared to their counterparts (7-12). The occurrence of metastatic disease, however, is similar between genders (7-13).

In contrast, UTUC is only 1.5-2 times more common in men than women $(14,15)$. In some Balkan regions females more often present UTUC, when compared to males. The underlying pathophysiologic mechanism has not fully been unveiled yet (see section: Geographical distribution and associated risk factors) $(16,17)$.

\section{Age}

$\mathrm{BC}$ is generally a disease of the elderly, with a median age at approximately 70 years at diagnosis $(18,19)$. In line with $\mathrm{BC}$, the incidence of UTUC increases with patient age with a peak incidence at 70-90 years. Not surprisingly, increasing age at diagnosis has been associated with inferior outcomes (20).

\section{Geographical distribution and associated risk factors}

The incidence of urothelial BC is enriched in developed countries. In contrast, the incidence of squamous cell carcinoma of the urinary bladder is high in some African and Asian countries because of endemic Schistosomiasis (21). Tobacco smoking significantly increases the risk of both BC and UTUC and is responsible for half of the BC cases in some populations $(18,22,23)$.

The prevalence of UTUC is regionally enriched in Balkan and Asian regions such as Taiwan (24). The underlying rationale for this enrichment has not fully been unravelled. An association of UTUC and black foot disease or a high content of arsenic in the drinking water is assumed. Since the 1950, also in Balkan regions a high incidence of UTUC has been described (in some areas 60-100 times higher than the rest of the world) (25). Both, this so called Balkan endemic nephropathy as well as the Chinese herbs nephropathy (CHN), are chronic tubulointerstitial renal diseases that are associated with an increased risk of UTUC (26). Both have been linked to an exposure to aristolochic acid, which has nephrotoxic and carcinogenic effects. These above mentioned parameters are considered to cause an increased incidence of UTUC in females (see section: Gender).

\section{Pathological differences (Table 2)}

Urothelium covers the urinary tract from the intrarenal collecting system, ureter, bladder and urethra. Basal stem cells of the urothelium proliferate and differentiate to luminal and finally umbrella cells. During this maturation, UC can arise from each cell phenotype. Consequently, UC presents a wide range of phenotypes and different histomorphologic characteristics (27). The World Health Organisation Classification of Tumours of the Urinary System and Male Genital Organs of 2016 classified no more than 13 different histological variants (28). Some histological variants are associated with an unfavourable prognosis (29). However, the current clinical management is only minimally affected by these different morphological patterns. Although mainly characterized in $\mathrm{BC}$, the histological variants are also used to describe UTUC.

Most BC present a pure or conventional urothelial 
Table 1 Clinical characteristics

\begin{tabular}{|c|c|c|}
\hline & $\mathrm{BC}$ & UTUC \\
\hline \multicolumn{3}{|l|}{ Epidemiology } \\
\hline Peak incidence (y) & 80 & 80 \\
\hline Percentage of all UC & $90-95 \%$ & $5-10 \%$ \\
\hline Men:women ratio & $3-4: 1$ & $1.5-2: 1$ \\
\hline \multicolumn{3}{|l|}{ Risk factors } \\
\hline Tobacco smoking & Yes & Yes \\
\hline Chronic urothelial infection & Yes & Possible \\
\hline Aristolochic acid & Possible & Yes \\
\hline Genetic factors & Only scarcely explored & Lynch syndrome \\
\hline Arsenic in drinking water & Possible & Possible \\
\hline Others & $\begin{array}{l}\text { Thiazolidinediones, metabolic disorders, chlorinated } \\
\text { drinking water }\end{array}$ & Alcohol consumption \\
\hline \multicolumn{3}{|l|}{ TNM classification } \\
\hline T-stadium & Subclassification for T2, T3 and T4 & No subclassification \\
\hline Cystoscopy and urinary cytology & Yes & Yes \\
\hline $\begin{array}{l}\text { Transurethral resection of invasive bladder } \\
\text { tumours (TURBT) }\end{array}$ & Yes & if suspected BC \\
\hline $\begin{array}{l}\text { Diagnostic ureteroscopy with biopsy and/or } \\
\text { selective cytology }\end{array}$ & If suspected UTUC & Yes \\
\hline $\begin{array}{l}\text { Staging with lung- and abdominal computed } \\
\text { tomography (or Magnetic resonance urography) }\end{array}$ & Yes & Yes \\
\hline
\end{tabular}

BC, bladder urothelial carcinomas; UTUC, upper urinary tract urothelial carcinomas; UC, urothelial carcinomas.

histology and a third of the urothelial BC show a concomitant variant histology (28). They are often associated with high grade disease and locally advanced stages (30,31). In contrast, in UTUC only a quarter of the carcinomas present variant histology $(32,33)$. In line to BC, they seem to represent more aggressive biological features and are independent risk factors for unfavourable prognosis (34).

Finally, there are minimal differences in the TNM classification between BC and UTUC (35). In BC, infiltration into the detrusor muscle $(\mathrm{pT} 2 \mathrm{a} / \mathrm{b})$, the 
Table 2 Pathological and molecular features

\begin{tabular}{|c|c|c|}
\hline Feature & $\mathrm{BC}$ & UTUC \\
\hline Classification & $\begin{array}{l}\text { According to the World Health Organisation } \\
\text { and Male Genital Organs of } 2016\end{array}$ & Classification of Tumours of the Urinary System \\
\hline Conventional:variant & 90-70\%:10-30\% & $75 \%: 25 \%$ \\
\hline \multicolumn{3}{|l|}{ Molecular features } \\
\hline Mutations in NMIBC & $\begin{array}{l}\text { FGFR3, Chromosome } 9 \text { loss of } \\
\text { heterozygosity, PIK3CA, Ras gene } \\
\text { mutations }\end{array}$ & \\
\hline High-grade UTUC & & $\begin{array}{l}\text { FGFR3 (more frequently mutated in UTUC than BC), } \\
\text { TP53, HRAS, KMT2D, CDKN2B, ARID1A }\end{array}$ \\
\hline Classifications & $\begin{array}{l}\text { Baylor, UNC, MDA, TCGAC, CIT-Curie and } \\
\text { Lund }\end{array}$ & $\begin{array}{l}\text { Single study subtype classification proposed. } \\
\text { Relevant heterogeneity and no association with } \\
\text { molecular subtypes of BC }\end{array}$ \\
\hline Consensus classification & $\begin{array}{l}\text { In 2020, six classes: luminal papillary } \\
\text { (LumP, 24\%), luminal nonspecified } \\
\text { (LumNS, 8\%), luminal unstable (LumU, } \\
\text { 15\%), stroma-rich (15\%), basal/squamous } \\
\text { (Ba/Sq, 35\%), and neuroendocrine-like } \\
\text { (NE-like, 3\%) }\end{array}$ & No consensus classification \\
\hline
\end{tabular}

BC, bladder urothelial carcinomas; UTUC, upper urinary tract urothelial carcinomas; MIBC, muscle-invasive bladder cancer; NMIBC, non-muscle-invasive bladder cancer.

perivesical fat $(\mathrm{pT} 3 \mathrm{a} / \mathrm{b})$ and adjacent organs $(\mathrm{pT} 4 \mathrm{a} / \mathrm{b})$ are further classified and acknowledged in different primary tumor stages. Number and location of lymph node metastases is taken into account to quantify three different stages in case of involvement. Finally, metastatic BC is differentiated into non-regional lymph nodes and other metastasis. Differences in the TNM staging of UTUC are that likely due to the thinner smooth muscle layer, a further subclassification into pT2a and b is not performed. Also infiltration beyond the muscle layer and adjacent organs are not further distinguished. Number as well as size of lymph node metastases are considered and classified into two $\mathrm{pN}$ stages in case of lymph node involvement. Finally, in contrast to $\mathrm{BC}$, no further subclassification of metastatic UTUC is performed.

\section{Molecular landscape of advanced UC (Table 2)}

Large-scale tumor profiling of BC and UTUC dramatically improved our understanding of their molecular landscape. Moreover, these investigations suggested clinical implications on diagnostic and therapeutic strategies. UC of the bladder is 10 to 20 times more frequent than in the upper urinary tract and for this reason the emerging evidence on biology of UC using high-throughput molecular profiling is mainly due to studies on BC. Highthroughput sequencing technologies and publicly accessible large-scale molecular databases [e.g., The Cancer Genome Atlas (TCGA), International Cancer Genomics Consortium (ICGC), Pan-Cancer Analysis of Whole Genomes (PCAWG)] and dataset generated from single centers 
offered an extraordinary opportunity in understanding cancer biology. Breast and lung cancer have been the first malignancies that were classified into clusters based on molecular characteristics (36). These concepts contributed to the understanding of tumor pathogenesis. Moreover, the discovery of these so called molecular subtypes contributed to the discovery of prognostic biomarkers and the possibility to predict treatment response. Finally, they allowed even the development of tumor-specific targeted therapies (37).

\section{Bladder}

Investigations on phenotypic variants and the prevalence of occult mutational signatures revealed the remarkable heterogeneity of $\mathrm{BC}$ more than a decade ago. Based on biological characteristics dependent on molecular pathways and clinical outcomes suggested a two pathway model for tumor pathogenesis: papillary tumors, in the clinical practice frequently non-muscle-invasive bladder cancer (NMIBC) and flat/non-papillary tumors, similar to muscleinvasive tumors $(38,39)$. Approximately three quarters of BC are non-muscle invasive and most of them are characterized by a papillary histology with near-diploid karyotype and few genomic rearrangements. Frequent mutations associated with NMIBC are FGFR3 (in up to $80 \%$ of pTa tumors), Chromosome 9 loss of heterozygosity (LOH) (32-48\%), PIK3CA (25\%) and Ras gene mutations (HRAS, KRAS2, $N R A S)$. TP53 alterations seem to play a major role in highgrade tumors and MIBC, and have been associated with progression of NMIBC in MIBC. However, progression from NMIBC to MIBC also occurs in genetically stable BC, likely due to CDKN2A loss. Multitudes of other genes have been described in the pathogenesis of NMIBC: TERT, CCND1, CCND3, FGFR1, ARID1A, ERBB2, etc. (40-46).

In the two-pathway model, invasive urothelial cancer seemed to arise through a distinct mechanism than papillary and NMIBC. In MIBC, molecular analysis suggested that flat dysplasia may precede development of UC in situ (CIS) and finally invasive UC (47).

TP53 and 9p and 9q LOH play a crucial role in the early pathogenesis of CIS (48). TP53 is commonly mutated in CIS (72\%) and is inactivated in $76 \%$ of MIBC. Chromosome 9 deletions are frequently present in CIS and MIBC $(40,48)$.

This two-pathway approach was a first step in understanding the evolution of UC, but did not lead to any concrete consequence in the clinical practice. In 2016, Hedegaard et al. classified NMIBC into three molecular subtypes (class I, II and III) (49). Class I tumors showed the best prognosis and luminal characteristics whereas class II tumors showed also luminal characteristics but an inferior prognosis and genomic instability (e.g., TP53 loss, ERCC2 mutations). Both classes can also be identified in MIBC (class I - Luminal papillary, class II - Luminal unstable). This may help to refine the two-pathway model and to explain the evolution of bladder cancer. Contrarily, class III tumors presented with a basal like phenotype and did not show similarities to molecular characteristics identified in MIBC (50). The Lund group was the first to attempt a molecular classification system in BC (51). An increase in the size or their dataset revealed a finer grained classification system to five subtypes (52). Finally, five years later, they were also the first that identified the neuroendocrine-like subtype (53).

In 2014, TCGA published their initial analysis of a multiplatform analysis of $131 \mathrm{MIBC}$ (54). They identified two basal and two luminal subtypes. In 2017, after an extension of their cohort to 412 MIBC, they updated their classification system and proposed five molecular subtypes (55).

In 2014, Choi et al. (MDA group) proposed, reminiscent of breast cancer molecular subtyping, a subclassification of MIBC in basal, luminal and "p53-like" subtypes (56).

Also in 2014, Damrauer et al. (UNC group) proposed a 47 -gene set predictor in the effort to identify and predict molecular and clinically subtypes within high-grade UC. They defined two distinct molecular subtypes: luminal and basal-like. A claudin-low subset of tumors was also noted and led the same group in 2016, to propose a third distinct molecular subtype characterized by low expression levels of claudins $(57,58)$.

Although all proposed subtyping classifications share a common concept of subdivision between a basal and luminal tumors, an evident heterogeneity in the further subtypes exists. In tumors with high mutation frequency, like UC, >3,000 samples might be needed to detect a distinct rare subtype with a frequency of $<2 \%$ (59). Growing cohort numbers imply an increase in detection of further subtypes, like observed for example in the TGCA and Lund classification during the years. Another major limitation is that all proposed classifications are characterized by heterogeneity when considering the studied populations, with either classifications based on MIBC, NMIBC or both together. Furthermore over the time there was growing evidence that microenvironment and non-tumor cells play a major role in the global understanding of UC.

All these aspects are especially relevant if we consider improvement of treatment and focus on personalized oncology 
as the main goals. While expanding the cohorts, the need for unified classification was growing and was an urgently needed step: a consensus classification allows the transfer of molecular subtyping into clinical practice and precision oncology, and unifies the terminology for future studies.

In 2020 a consensus molecular classification of MIBC, based on 1750 MIBC transcriptomic profiles from 16 published datasets, has proposed six molecular classes: luminal papillary (LumP, 24\%), luminal nonspecified (LumNS, 8\%), luminal unstable (LumU, 15\%), stroma-rich $(15 \%)$, basal/squamous $(\mathrm{Ba} / \mathrm{Sq}, 35 \%)$, and neuroendocrinelike (NE-like, 3\%). The classification was strongly associated with each of the input classification systems (Baylor, UNC, MDA, TCGAC, CIT-Curie and Lund). These classes present different molecular signatures, microenvironment infiltration, histological and clinical characteristics, as well as distinct outcomes (60).

\section{Upper tract urothelial carcinoma (UTUC)}

Compared to $\mathrm{BC}$, genetic analysis and high-throughput sequencing of UTUC is much less reported in the literature and few studies with genomic characterization of UTUC have been published.

In 2015, Sfakianos et al. (5) analyzed 83 tumor samples from patients with high-grade $(\mathrm{n}=60)$ and low-grade $(\mathrm{n}=23)$ UTUC treated with radical nephroureterectomy and $(\mathrm{n}=102)$ samples from BC in patients without history of UTUC. Cancerassociated genes and somatic mutations were evaluated and a comparison of the molecular profile between BC and UTUC was performed. The most frequent mutated genes in highgrade UTUC were FGFR3 (35.6\% vs. $21.6 \%$ in $\mathrm{BC}, \mathrm{P}=0.065$ ), TP53 (25.4\% vs. $57.8 \%$ in $\mathrm{BC}, \mathrm{P}<0.001)$, HRAS (13.6\% vs. $1.0 \% ; \mathrm{P}=0.001), C D K N 2 B$ (5.3\% vs. $3.9 \% ; \mathrm{P}=0.016$ ), ARID1A ( $27.5 \%$ vs. $13.6 \%, \mathrm{P}=0.050)$. The study showed that despite a similar spectrum of cancer-associated genes in BC and UTUC, there is a relevant heterogeneity in the prevalence of the mutations between the two entities (5).

In 2017, Moss et al. (61) published a comprehensive genomic analyses of low-grade ( $n=14)$ and high grade $(n=17)$ UTUC samples after endoscopic biopsy or surgical resection in 31 patients. The following mutation frequencies were reported FGFR3 (74.1\%; 92\% low-grade, 60\% high-grade), KMT2D (44.4\%), PIK3CA (25.9\%), and TP53 (22.2\%). Interestingly FGFR 3 was mutated in $60 \%$ of the invasive UTUC compared to $35.6 \%$ reported by Sfakianos et al. in 2015 (5). Furthermore, using unsupervised consensus clustering of RNAseq expression data, four molecular subtypes were generated with some similarities to the TCGA clusters for BC. Comparing these results to the TGCA 2014 classification, global mutation rate in BC and UTUC were similar $(54,61)$.

In 2018, Donahu et al. analyzed germline mutations in UTUC patients $(\mathrm{n}=17)$ with Lynch syndrome and compared the results with a cohort of 82 sporadic UTUC. Interestingly, after a pathological review of the sections, they found no variant histology in their UTUC cohort. In line with the underlying biology of Lynch syndrome, UTUC in these patients are associated with a significant higher mutational burden as well as higher frequency of genomic alterations in KMT2D, CREBBP, $A R I D 1 A$ or in DNA damage response and repair genes. Contrarily, mutations in CIC, NOTCH1, NOTCH3, RB1, and $C D K N 1 B$ genes were only found in the control population (62). Robinson et al. compared in 2019 genomic analysis from patients with high-grade UTUC ( $\mathrm{n}=37)$, with data from BC tumors from the TCGA cohort. As already observed FGFR3 was less frequently mutated in high-grade BC (13.7\%) compared to high-grade UTUC (29.7\%). In contrast, no significant difference in the prevalence of mutations between UTUC and BC were reported for KMT2D, ARID1A, KDM6A, PIK3CA, HRAS, RXRA, KLF5, ELF3, TP53, RB1, $C D K N 1 A, C D K N 2 A$. UTUC were consistently luminalpapillary and T-cell depleted, which seems to be related with an unfavorable response to checkpoint inhibitors (63).

Audenet et al. performed a genomic analysis in 454 BC (94\% high-grade) and 195 UTUC (85\% high-grade) patients, and investigated clonal similarities of 29 patients with metachronous UTUC and BC. Overall, FGFR3 and HRAS were more frequently mutated in UTUC ( $40 \%$ vs. $26 \%, 12 \%$ vs. 4\%, respectively; $\mathrm{Q}<0.001), T P 53, R B 1$, and $E R B B 2$ were more frequently mutated in BC ( $46 \%$ vs. $26 \%, 20 \%$ vs. $3 \%$, $19 \%$ vs. $8 \%$, respectively; $\mathrm{Q}<0.001)$. The mutational burden was significantly higher in UTUC compared with BC, with patients presenting Lynch syndrome associated gene mutation showing high mutational burden. Clonal relatedness was confirmed for all $(\mathrm{n}=29)$ patients with bladder recidivism, with a concordance of $86 \%$ of somatic mutations in both the initial UTUC and the subsequent BC (64).

\section{Therapies and the role of high-throughput molecular profiling (Table 3)}

\section{Therapy of BC in 2020}

The standard of care for the treatment of NMIBC contains transurethral resection of the bladder tumor (TURBT). 
Table 3 Therapies and outcomes

\begin{tabular}{|c|c|c|}
\hline & $\mathrm{BC}$ & UTUC \\
\hline Low-grade & $\begin{array}{l}\text { TURBT + single post-operative intravesical } \\
\text { instillation of chemotherapy }\end{array}$ & $\begin{array}{l}\text { Endoscopic ablation (e.g., by laser ablation); CAVE: absence of } \\
\text { hydronephrosis, tumor size }<2 \mathrm{~cm} \text {, solitary disease, absence of } \\
\text { variant histology and absence of previous high-grade tumors }\end{array}$ \\
\hline High-grade & $\begin{array}{l}\text { TURBT + second TURBT ( } 2-6 \text { weeks) and + } \\
\text { Instillation Therapy (BCG > Chemotherapy) }\end{array}$ & See muscle invasive UTUC \\
\hline Primary CIS & $\begin{array}{l}\text { TURBT + Instillation Therapy (BCG > } \\
\text { Chemotherapy) }\end{array}$ & See muscle invasive UTUC \\
\hline \multicolumn{3}{|c|}{ Therapy muscle invasive } \\
\hline $\begin{array}{l}\text { Neoadjuvant } \\
\text { chemotherapy }\end{array}$ & $\begin{array}{l}\text { Indicated in T2-T4a, cNOM0 with cisplatin-based } \\
\text { combination therapy }\end{array}$ & To date, no prospective trial has been published on this topic \\
\hline Surgery & $\begin{array}{l}\text { Radical cystectomy }(\mathrm{RC}) \text {, pelvic } \\
\text { lymphadenectomy and subsequent urinary } \\
\text { diversion }\end{array}$ & $\begin{array}{l}\text { Nephroureterectomy with excision of bladder cuff and regional } \\
\text { lymphadenectomy and single postoperative intravesical instillation } \\
\text { with chemotherapy }\end{array}$ \\
\hline Adjuvant therapy & $\begin{array}{l}\text { Limited to patients with } \mathrm{pT} 3 / 4 \text { and/or } \mathrm{N}_{+} \\
\text {disease without metastases with cisplatin-based } \\
\text { combination therapy }\end{array}$ & $\begin{array}{l}\text { The POUT trial showed that platinum-based chemotherapy } \\
\text { significantly improved disease-free survival in locally advanced } \\
\text { UTUC }\end{array}$ \\
\hline $\begin{array}{l}\text { Adjuvant } \\
\text { immunotherapy }\end{array}$ & $\begin{array}{l}\text { Investigated in many clinical trials, but data have } \\
\text { not been published yet }\end{array}$ & To date, no prospective trial has been published on this topic \\
\hline Alternatives & $\begin{array}{l}\text { Bladder preserving therapies, like multimodality } \\
\text { treatment (MMT) which combines transurethral } \\
\text { maximal resection, chemo- and radiotherapy }\end{array}$ & $\begin{array}{l}\text { Segmental ureterectomy with reimplantation of the ureter (provide } \\
\text { similar outcomes as RNU, with the advantage of preserving } \\
\text { kidney function) }\end{array}$ \\
\hline \multirow{3}{*}{$\begin{array}{l}\text { Recurrence and risk } \\
\text { factors }\end{array}$} & $\begin{array}{l}\text { Risk factors: presence of CIS, High-grade } \\
\text { features, stage T1 tumor, number of tumors, } \\
\text { tumor diameter, prior recurrence rate }\end{array}$ & $\begin{array}{l}\text { Risk factors: advanced age, male gender, ureteral tumor location, } \\
\text { laparoscopic surgical technique, endoscopic distal ureteral } \\
\text { management, previous bladder cancer, higher tumor stage, } \\
\text { concomitant carcinoma in situ (CIS), and lymph node involvement } \\
\text { (LVI) }\end{array}$ \\
\hline & $\begin{array}{l}\text { MIBC: Distant recurrence is seen in up to } 50 \% \text { of } \\
\text { patients treated with RC for MIBC }\end{array}$ & Distant recurrence: after RNU 20-65\% \\
\hline & $\begin{array}{l}\text { Risk factors: advanced disease and nodal } \\
\text { involvement }\end{array}$ & $\begin{array}{l}\text { Risk factors: Concomitant CIS, LVI, higher tumor stage, } \\
\text { multifocality }\end{array}$ \\
\hline \multirow{4}{*}{$\begin{array}{l}\text { The } 5 \text {-year specific } \\
\text { survival }\end{array}$} & $\mathrm{pTa} / \mathrm{pTis} / \mathrm{pT} 1>75 \%$ & $\mathrm{pTa} / \mathrm{pTis} / \mathrm{pT} 1>90 \%$ \\
\hline & pT2/pT3 50-75\% & pT2/pT3: $<50 \%$ \\
\hline & pT4 $<50 \%$ & pT4/M1 <10\% \\
\hline & $M 1<10 \%$ & \\
\hline
\end{tabular}

BC, bladder urothelial carcinomas; UTUC, upper urinary tract urothelial carcinomas. 
In case of low risk disease, an early postoperative chemotherapy instillation of the bladder reduces risk of recurrence. In high risk disease, a confirmation TURBT is suggested, followed by intravesical instillations with BCG $(65,66)$. The first-line treatment of CIS is not surgical but performed with BCG instillations with a complete response rate in $72-93 \%$ patients (67-69). One in two patients with initial complete response is likely to show recurrence with the need of further installation therapies or RC $(68,70,71)$.

The standard of care for the treatment of MIBC contains radical cystectomy, pelvic lymph node dissection and urinary diversion $(6,72)$.

To improve patient outcomes, perioperative chemotherapy has been investigated. Cisplatin based neoadjuvant chemotherapy, which has been used since 1980s, was studied in several RCTs which demonstrated a statistically relevant survival advantage in patients with MIBC prior to surgery. A recent meta-analysis on $(n=3,285)$ patients compared clinical outcomes of MVAC: methotrexate, vinblastine, doxorubicin, and cisplatin $v s$. GC: gemcitabine and cisplatin/carboplatin in the neoadjuvant setting. Cisplatin-based neoadjuvant chemotherapy showed a $16 \%$ reduction in overall death risk, compared with locoregional therapy alone and absolute survival benefit of $8 \%$ at 5 years $(6,73,74)$.

Neoadjuvant immunotherapy is increasingly being tested in the neoadjuvant setting either in platinum-ineligible patients or as combination therapy. The use of checkpoint inhibitors is already approved as first-line treatment in patients ineligible (unfit) for cisplatin and as secondline immunotherapy for platinum-pre-treated patients with progressing metastatic UC. Based on the results of checkpoint inhibitors in metastatic UC, several clinical trials are investigating the role of novel immunotherapeutic approaches in the preoperative setting. The preliminary results of a Phase II study using the PD-1 inhibitor pembrolizumab in the neoadjuvant setting for MIBC before $\mathrm{RC}$ showed promising results with complete pathological remission (pT0) in $42 \%$ of patients. programmed death ligand 1 (PD-L1)-expressing or high-Total mutational burden were both predictors of clinical response (75).

The role of adjuvant cisplatin-based chemotherapy in MIBC is limited to patients with $\mathrm{pT} 3 / 4$ and/or LN positive $(\mathrm{N}+)$ disease without metastases (cM0). Evidence supporting the use of adjuvant chemotherapy in MIBC is limited and not conclusive $(6,76,77)$. In 2014, a meta-analysis based on 945 patients from nine trials, evaluated outcomes in patients receiving adjuvant chemotherapy after RC. Despite the trials were characterized by relevant methodological flaws and different chemotherapy protocol, this metaanalysis concluded an overall survival [pooled hazard ratio (HR): 0.77; 95\% CI, 0.59-0.99; $\mathrm{P}=0.049]$ and disease-free survival (HR: 0.66; 95\% CI, 0.45-0.91; $\mathrm{P}=0.014$ ) benefit in patients with MIBC receiving adjuvant cisplatin-based chemotherapy after RC. The impact on DFS in patients with nodal involvement was more evident (76).

Furthermore, a multi-center, phase 3 trial of 284 patients with non-metastatic MIBC randomly assigned either to immediate adjuvant cisplatin-based chemotherapy or deferred chemotherapy at relapse showed significant prolonged progression-free survival for immediate treatment (HR 0.54; 95\% CI, 0.4-0.73; $\mathrm{P}<0.0001$ ), without significant difference in overall survival (78).

To summarize, the role of adjuvant chemotherapy in the treatment of MIBC remains unclear. Based on the current evidence, immediate cisplatin-based adjuvant chemotherapy after cystectomy seems to improve outcomes, especially in non-variant histology and high-risk groups with nodal involvement and extravesical extension.

Adjuvant immunotherapy is investigated in many clinical trials, but data have not been published yet.

\section{UTUC in 2020}

According to the EAU Guidelines, low-risk UTUC is defined by: absence of hydronephrosis, tumor size $<2 \mathrm{~cm}$, low-grade cytology or URS biopsy, solitary disease, absence of variant histology and absence of previous high-grade tumors (14).

In low-risk UTUC, nephron-sparing treatment, e.g., by laser ablation can be offered (79). Whether a single early postoperative instillation of a chemotherapeutic agent (retrograde through a SJ or DJ) would prevent recurrence has been investigated in only one non-controlled study based on which a final recommendation cannot be made (80). In case of CIS in the upper urinary tract, the instillation of BCG has been investigated $(14,81,82)$. Only scarce evidence exists for the success of this treatment approach and a more recent publication even questions the responsiveness of CIS in the upper urinary tract to BCG (83). However, it is questionable, if one can justify radical surgery for CIS only in the upper urinary tract as treatment in the first-line.

In case of high-risk UTUC radical surgery is recommended. This includes nephroureterectomy with excision of bladder cuff and regional lymphadenectomy. In selected cases with tumors located in the ureter or 
patient with solitary kidney or compromised renal function, treatment with kidney-sparing surgery can be offered.

For organ confined tumors located in the ureter, segmental ureterectomy (SU) with reimplantation of the ureter has been shown to provide similar outcomes as RNU, with the advantage of preserving kidney function $(14,84)$. In 2016, a meta-analysis of 11 retrospective studies with $3,963$ patients who underwent either SU ( $\mathrm{n}=983 ; 24.8 \%)$ or RNU ( $\mathrm{n}=2,980 ; 75.2 \%)$ reported no significant differences in terms of CSS and OS between both groups, with SU providing a significant decreased risk of postoperative renal function impairment (85). However, these results should be interpreted with caution, because patients undergoing kidney-sparing techniques often present with favorable clinical and oncological characteristics compared to patients undergoing RNU, which can generate selection bias.

Oncological outcomes between open and laparoscopic RNU have been studied in a systematic review of 42 studies in 2019 (86). Among 7,554 patients, 4,925/7,554 (65\%) underwent open RNU and 2,629/7,554 (35\%) laparoscopic RNU. They concluded that in a subgroup of patients with non-organ confined UTUC (pT3/pT4) as well as in patients with laparoscopic bladder cuff removal, oncological outcomes of laparoscopic RNU tend to be poorer compared to open RNU.

Intravesical recurrence (IVR) after radical surgery for UTUC occurs in $22-47 \%$ of the cases $(14,87)$. To prevent intravesical tumor-cell dissemination after manipulation and surgery of advanced UTUC, the effect of a single postoperative intravesical instillation with chemotherapy (mitomycin C, pirarubicin) has been studied in a metaanalysis in 2013 (88). In five trials on 614 patients, with a median follow-up of 12, 55.6, 46 and 45 months (data were incomplete in one trial), IVR was present in 55/268 (20.5\%) patients who received postoperative instillation and 127/346 (36.7\%) who had no postoperative instillation, with a significant decrease of $41 \%$ in the odds of recurrence.

Perioperative systemic treatment in UTUC is not studied to a similar extent as in BC.

Based on the observations and results obtained through neoadjuvant chemotherapy in the treatment of bladder carcinoma, several retrospective studies have investigated the role of neoadjuvant therapy in UTUC. Utilizing preoperative cisplatin-based chemotherapy, pathological downstaging as well as lower recurrence rates and better outcomes have been observed (14,89-92). To date, no prospective trial has been published on this topic.

Similarly adjuvant chemotherapy for UTUC has been investigated based on data adopted from BC. A limitation of cisplatin-based chemotherapy in the adjuvant setting is given by the patient's kidney function, which may be impaired or reduced in patients after RNU. To date only one prospective study has been published on adjuvant systemic chemotherapy for UTUC. In 2020 the results of a multi-center, randomised study of 261 patients with UTUC after RNU staged as either pT2-T4 pN0-N3 M0 or pTany $\mathrm{N} 1-3 \mathrm{M} 0$, were randomly assigned to either surveillance or platinum-based chemotherapy. Chemotherapy conferred a $55 \%$ reduction in relative risk of disease recurrence or death. At a median follow-up of 30.3 months, adjuvant chemotherapy significantly improved 3 -year DFS (71\% in the chemotherapy group $v s .46 \%$ in the surveillance group). Based on these results, potential similar survival advantages should also be expected in the neoadjuvant therapy, but further prospective studies are needed (93).

\section{Future development, high-throughput molecular profiling and personalized therapies}

During the last decade, the first studies on molecular phenotyping were descriptive and aimed to allocate bladder cancer in subgroups that were considered to harbor common molecular and clinical characteristics. The technological advancements in genomic profiling as well as the development of machine learning algorithms and software to process the large amount of data, provided the ability to generate subtyping models and interpret these results. Despite all efforts, the transfer of knowledge into clinical practice is an inevitably long process, made complex by the heterogeneity of the study populations as well as the relative rarity especially of UTUC. This process is still ongoing and only few, but significant, innovations have been made in the treatment of UC.

Choi et al., published in 2014 the first study attempting to investigate the sensitivity of three distinct molecular subtypes (basal, p53-like, luminal) to conventional cisplatinbased neoadjuvant chemotherapy. They observed that "p53-like" MIBCs were consistently resistant to frontline NAC. Basal subtype tumors that responded to NAC were enriched with biomarkers reflective of immune infiltration, and luminal tumors partly responded to NAC but for this subtype pretreatment gene signatures could not be found (56). The same group in 2016 investigated clinical outcomes in 60 patients receiving dose-dense cisplatin-based NAC in addition to Bevacizumab. They allocated $(n=38)$ preNAC TURBT specimens using the three molecular 
subtype panels previously described. "p53-like" tumors had again poorer outcomes (5-yr OS: 36\%) and higher rate of metastasis following NAC compared to basal (5-yr OS: 91\%) and luminal tumors (5-yr OS: 73\%) (94).

An important limitation for clinical implementations of these results, is that molecular phenotyping is based on relative gene expression. The need to analyse an entire cohort in order to assign a tumor to his subtype limits substantially the use in the clinical practice. To address this issue, in 2017, Seiler et al. proposed a singlesample classifier to predict bladder cancer subtype based on transcriptomic analysis of TURBT specimens. They correlated the outcomes after NAC in a large multicenter cohort $(n=269)$ with molecular subtyping of preNAC specimens and confirmed the clinical utility of four subtypes: claudin-low (is a EMT and immune infiltrated subgroup of basal tumors with poor outcomes, regardless of NAC), basal (showed most benefit from NAC with dramatically improved outcomes), luminal-infiltrated (appear to have poor prognosis with and without NAC), luminal (had the best prognosis non-treatment dependent, question the utility of NAC) (95).

Chemoresistance to standard cisplatin-based protocols highlighted the need of trials to investigate alternative therapies as well as the need of biomarkers to predict response.

In the IMvigor 210 trial, patients with inoperable locally advanced or metastatic UC whose disease had progressed after platinum-based chemotherapy, were treated with atezolizumab, a monoclonal antibody that binds selectively to PD-L1. Surprisingly the neuronal subtype, which was associated with the worst survival in the TCGA 2017 cohort, had the best overall survival among the five subtypes in the atezolizumabtreated cohort $(96,97)$.

A phase II trial on 270 patients with platinum-based chemotherapy resistant metastatic or unresectable UC showing disease progression, investigated response to the PD-1 human IgG4 monoclonal antibody Nivolumab. The greater response to Nivolumab was in the TGCA III subtype where $30 \%$ of the patients had complete or partial responses (98).

The ABACUS trial was not able to show different pathological response among different subtypes based on the Lund classification in patients $(\mathrm{n}=95)$ with MIBC receiving two cycles of atezolizumab before cystectomy (99).

The use of checkpoint-inhibitors for advanced or metastatic UC are established in the clinical practice based on data from two phase III randomized trials (NCT02853305, NCT02302807). Many potential biomarkers to predict response to immunotherapy have been investigated: molecular subtypes, PD-L1 status, TMB, immune infiltration, DNA gene repair status, etc. (100). However, none of these has shown to date enough reproducibility and reliability to be applied alone in the clinical practice and further evidence is needed.

High-throughput molecular profiling of BC and UTUC allowed us to better understand the mechanisms that drive the biology of UC. At clinical, morphological and molecular level, BC seems to represent differences compared to UTUC. Moreover, mutational signatures were repetitively found in different frequencies in BC and UTUC. This is currently not taken into account in clinical practice and UC are treated with only limited distinction of the anatomical location of the tumor.

\section{Conclusions}

Taken together, despite similarities of BC and UTUC, clinicopathologic and molecular differences may question to generally assemble both in the same tumor entity.

Treatment standards for UTUC are often adopted from BC. However, a specific investigation in the former may still be meaningful as shown by the example of adjuvant cisplatin based chemotherapy.

Future investigations should prioritize in the understanding of the tumor biology of both. This may reveal which UTUC can be treated according to treatment standards of BC and in which cases, a separate approach may be more appropriate.

\section{Acknowledgments}

Funding: Swiss National Science Foundation Grant Nr. 310030_184933.

\section{Footnote}

Provenance and Peer Review: This article was commissioned by the Guest Editor (Tilman Todenhöfer) for the series "Management of Advanced Genitourinary Malignancies" published in Translational Andrology and Urology. The article has undergone external peer review.

Reporting Checklist: The authors have completed the Narrative Review reporting checklist. Available at http:// dx.doi.org/10.21037/tau-20-1472

Conflicts of Interest: All authors have completed the ICMJE uniform disclosure form (available at http://dx.doi. 
org/10.21037/tau-20-1472). The series "Management of Advanced Genitourinary Malignancies" was commissioned by the editorial office without any funding or sponsorship. The authors have no conflicts of interest to declare.

Ethical Statement: The authors are accountable for all aspects of the work in ensuring that questions related to the accuracy or integrity of any part of the work are appropriately investigated and resolved.

Open Access Statement: This is an Open Access article distributed in accordance with the Creative Commons Attribution-NonCommercial-NoDerivs 4.0 International License (CC BY-NC-ND 4.0), which permits the noncommercial replication and distribution of the article with the strict proviso that no changes or edits are made and the original work is properly cited (including links to both the formal publication through the relevant DOI and the license). See: https://creativecommons.org/licenses/by-nc-nd/4.0/.

\section{References}

1. Ferlay J, Steliarova-Foucher E, Lortet-Tieulent J, et al. Cancer incidence and mortality patterns in Europe: estimates for 40 countries in 2012. Eur J Cancer 2013;49:1374-403.

2. Siegel RL, Miller KD, Jemal A. Cancer statistics, 2020. CA Cancer J Clin 2020;70:7-30.

3. Gakis G, Witjes JA, Compérat E, et al. EAU guidelines on primary urethral carcinoma. Eur Urol 2013;64:823-30.

4. Stewart GD, Bariol SV, Grigor KM, et al. A comparison of the pathology of transitional cell carcinoma of the bladder and upper urinary tract. BJU Int 2005;95:791-3.

5. Sfakianos JP, Cha EK, Iyer G, et al. Genomic characterization of upper tract urothelial carcinoma. Eur Urol 2015;68:970-7.

6. Witjes JA, Bruins HM, Cathomas R, et al. European Association of Urology Guidelines on Muscle-invasive and Metastatic Bladder Cancer: Summary of the 2020 Guidelines. Eur Urol 2021;79:82-104.

7. Shariat SF, Sfakianos JP, Droller MJ, et al. The effect of age and gender on bladder cancer: a critical review of the literature. BJU Int 2010;105:300-8.

8. Mungan NA, Kiemeney LA, van Dijck JA, et al. Gender differences in stage distribution of bladder cancer. Urology 2000;55:368-71.

9. Fajkovic H, Halpern JA, Cha EK, et al. Impact of gender on bladder cancer incidence, staging, and prognosis.
World J Urol 2011;29:457-63.

10. Horstmann M, Witthuhn R, Falk M, et al. Gender-specific differences in bladder cancer: a retrospective analysis. Gend Med 2008;5:385-94.

11. Waldhoer T, Berger I, Haidinger G, et al. Sex Differences of $\geq$ pT1 Bladder Cancer Survival in Austria: A Descriptive, Long-Term, Nation-Wide Analysis Based on 27,773 Patients. Urol Int 2015;94:383-9.

12. Liu S, Yang T, Na R, et al. The impact of female gender on bladder cancer-specific death risk after radical cystectomy: a meta-analysis of 27,912 patients. Int Urol Nephrol 2015;47:951-8.

13. Andreassen BK, Grimsrud TK, Haug ES. Bladder cancer survival: Women better off in the long run. Eur J Cancer 2018;95:52-8.

14. Rouprêt M, Babjuk M, Compérat E, et al. European association of urology guidelines on upper urinary tract urothelial carcinoma: 2017 update. Eur Urol 2018;73:111-22.

15. Shariat SF, Favaretto RL, Gupta A, et al. Gender differences in radical nephroureterectomy for upper tract urothelial carcinoma. World J Urol 2011;29:481-6.

16. Grollman AP, Shibutani S, Moriya M, et al. Aristolochic acid and the etiology of endemic (Balkan) nephropathy. Proc Natl Acad Sci USA 2007;104:12129-34.

17. Samardzic J, Hasukic S. Upper Urinary Tract Urothelial Cancer in Croatian and Bosnian Endemic Nephropathy Regions. Med Arch 2017;71:430-3.

18. Lughezzani G, Burger M, Margulis V, et al. Prognostic factors in upper urinary tract urothelial carcinomas: a comprehensive review of the current literature. Eur Urol 2012;62:100-14.

19. Schultzel M, Saltzstein SL, Downs TM, et al. Late age (85 years or older) peak incidence of bladder cancer. J Urol 2008;179:1302-5; discussion 1305.

20. Kim HS, Jeong CW, Kwak C, et al. Association between demographic factors and prognosis in urothelial carcinoma of the upper urinary tract: a systematic review and metaanalysis. Oncotarget 2017;8:7464-76.

21. Richters A, Aben K, Kiemeney L. The global burden of urinary bladder cancer: an update. World J Urol 2020;38:1895-904.

22. Cumberbatch MG, Rota M, Catto JWF, et al. The Role of Tobacco Smoke in Bladder and Kidney Carcinogenesis: A Comparison of Exposures and Meta-analysis of Incidence and Mortality Risks. Eur Urol 2016;70:458-66.

23. Freedman ND, Silverman DT, Hollenbeck AR, et al. Association between smoking and risk of bladder cancer among men and women. JAMA 2011;306:737-45. 
24. Soria F, Shariat SF, Lerner SP, et al. Epidemiology, diagnosis, preoperative evaluation and prognostic assessment of upper-tract urothelial carcinoma (UTUC). World J Urol 2017;35:379-87.

25. Colin P, Koenig P, Ouzzane A, et al. Environmental factors involved in carcinogenesis of urothelial cell carcinomas of the upper urinary tract. BJU Int 2009;104:1436-40.

26. De Broe ME. Chinese herbs nephropathy and Balkan endemic nephropathy: toward a single entity, aristolochic acid nephropathy. Kidney Int 2012;81:513-5.

27. Xylinas E, Rink M, Robinson BD, et al. Impact of histological variants on oncological outcomes of patients with urothelial carcinoma of the bladder treated with radical cystectomy. Eur J Cancer 2013;49:1889-97.

28. Humphrey PA, Moch H, Cubilla AL, et al. The 2016 WHO Classification of Tumours of the Urinary System and Male Genital Organs-Part B: Prostate and Bladder Tumours. Eur Urol 2016;70:106-19.

29. Veskimäe E, Espinos EL, Bruins HM, et al. What Is the Prognostic and Clinical Importance of Urothelial and Nonurothelial Histological Variants of Bladder Cancer in Predicting Oncological Outcomes in Patients with Muscleinvasive and Metastatic Bladder Cancer? A European Association of Urology Muscle Invasive and Metastatic Bladder Cancer Guidelines Panel Systematic Review. Eur Urol Oncol. 2019;2:625-42.

30. Genitsch V, Kollár A, Vandekerkhove G, et al. Morphologic and genomic characterization of urothelial to sarcomatoid transition in muscle-invasive bladder cancer. Urol Oncol 2019;37:573.e19-9.

31. Black PC, Brown GA, Dinney CPN. The impact of variant histology on the outcome of bladder cancer treated with curative intent. Urol Oncol 2009;27:3-7.

32. Mori K, Janisch F, Parizi MK, et al. Prognostic Value of Variant Histology in Upper Tract Urothelial Carcinoma Treated with Nephroureterectomy: A Systematic Review and Meta-Analysis. J Urol 2020;203:1075-84.

33. Rink M, Robinson BD, Green DA, et al. Impact of histological variants on clinical outcomes of patients with upper urinary tract urothelial carcinoma. J Urol 2012;188:398-404.

34. Kim JK, Moon KC, Jeong CW, et al. Variant histology as a significant predictor of survival after radical nephroureterectomy in patients with upper urinary tract urothelial carcinoma. Urol Oncol 2017;35:458.e9-15.

35. Brierley J, Gospodarowicz M, Wittekind C. TNM Classification of Malignant Tumours. 8th Edition. 2017.

36. Perou CM, Sørlie T, Eisen MB, et al. Molecular portraits of human breast tumours. Nature 2000;406:747-52 .

37. Zhao L, Lee VHF, Ng MK, et al. Molecular subtyping of cancer: current status and moving toward clinical applications. Brief Bioinform 2019;20:572-84.

38. Wu XR. Urothelial tumorigenesis: a tale of divergent pathways. Nat Rev Cancer 2005;5:713-25.

39. Spruck CH, Ohneseit PF, Gonzalez-Zulueta M, et al. Two molecular pathways to transitional cell carcinoma of the bladder. Cancer Res 1994;54:784-8.

40. Knowles MA, Hurst CD. Molecular biology of bladder cancer: new insights into pathogenesis and clinical diversity. Nat Rev Cancer 2015;15:25-41.

41. Junker K, Boerner D, Schulze W, et al. Analysis of genetic alterations in normal bladder urothelium. Urology 2003;62:1134-8.

42. Obermann EC, Meyer S, Hellge D, et al. Fluorescence in situ hybridization detects frequent chromosome 9 deletions and aneuploidy in histologically normal urothelium of bladder cancer patients. Oncol Rep 2004;11:745-51.

43. Simoneau M, LaRue H, Aboulkassim TO, et al. Chromosome 9 deletions and recurrence of superficial bladder cancer: identification of four regions of prognostic interest. Oncogene 2000;19:6317-23.

44. Juanpere N, Agell L, Lorenzo M, et al. Mutations in FGFR3 and PIK3CA, singly or combined with RAS and AKT1, are associated with AKT but not with MAPK pathway activation in urothelial bladder cancer. Hum Pathol 2012;43:1573-82.

45. Platt FM, Hurst CD, Taylor CF, et al. Spectrum of phosphatidylinositol 3-kinase pathway gene alterations in bladder cancer. Clin Cancer Res 2009;15:6008-17.

46. Ahmad I, Patel R, Liu Y, et al. Ras mutation cooperates with $\beta$-catenin activation to drive bladder tumourigenesis. Cell Death Dis 2011;2:e124.

47. Castillo-Martin M, Domingo-Domenech J, Karni-Schmidt O, et al. Molecular pathways of urothelial development and bladder tumorigenesis. Urol Oncol 2010;28:401-8.

48. Hartmann A, Schlake G, Zaak D, et al. Occurrence of chromosome 9 and p53 alterations in multifocal dysplasia and carcinoma in situ of human urinary bladder. Cancer Res 2002;62:809-18.

49. Hedegaard J, Lamy P, Nordentoft I, et al. Comprehensive Transcriptional Analysis of Early-Stage Urothelial Carcinoma. Cancer Cell 2016;30:27-42.

50. Minoli M, Kiener M, Thalmann GN, et al. Evolution of Urothelial Bladder Cancer in the Context of Molecular Classifications. Int J Mol Sci 2020;21:5670.

51. Lindgren D, Frigyesi A, Gudjonsson S, et al. Combined 
gene expression and genomic profiling define two intrinsic molecular subtypes of urothelial carcinoma and gene signatures for molecular grading and outcome. Cancer Res 2010;70:3463-72.

52. Sjödahl G, Lauss M, Lövgren K, et al. A molecular taxonomy for urothelial carcinoma. Clin Cancer Res 2012;18:3377-86.

53. Sjödahl G, Eriksson P, Liedberg F, et al. Molecular classification of urothelial carcinoma: global mRNA classification versus tumour-cell phenotype classification. J Pathol 2017;242:113-25.

54. Cancer Genome Atlas Research Network. Comprehensive molecular characterization of urothelial bladder carcinoma. Nature 2014;507:315-22.

55. Robertson AG, Kim J, Al-Ahmadie H, et al. Comprehensive Molecular Characterization of MuscleInvasive Bladder Cancer. Cell 2017;171:540-56.e25.

56. Choi W, Porten S, Kim S, et al. Identification of distinct basal and luminal subtypes of muscle-invasive bladder cancer with different sensitivities to frontline chemotherapy. Cancer Cell 2014;25:152-65.

57. Kardos J, Chai S, Mose LE, et al. Claudin-low bladder tumors are immune infiltrated and actively immune suppressed. JCI Insight 2016;1:e85902.

58. Damrauer JS, Hoadley KA, Chism DD, et al. Intrinsic subtypes of high-grade bladder cancer reflect the hallmarks of breast cancer biology. Proc Natl Acad Sci USA 2014;111:3110-5.

59. Hurst CD, Knowles MA. Bladder cancer: Multi-omic profiling refines the molecular view. Nat Rev Clin Oncol 2018;15:203-4.

60. Kamoun A, de Reyniès A, Allory Y, et al. A Consensus Molecular Classification of Muscle-invasive Bladder Cancer. Eur Urol 2020;77:420-33.

61. Moss TJ, Qi Y, Xi L, et al. Comprehensive genomic characterization of upper tract urothelial carcinoma. Eur Urol 2017;72:641-9.

62. Donahu TF, Bagrodia A, Audenet F, et al. Genomic Characterization of Upper-Tract Urothelial Carcinoma in Patients With Lynch Syndrome. JCO Precis Oncol 2018. doi: 10.1200/PO.17.00143.

63. Robinson BD, Vlachostergios PJ, Bhinder B, et al. Upper tract urothelial carcinoma has a luminal-papillary T-cell depleted contexture and activated FGFR3 signaling. Nat Commun 2019;10:2977.

64. Audenet F, Isharwal S, Cha EK, et al. Clonal Relatedness and Mutational Differences between Upper Tract and Bladder Urothelial Carcinoma. Clin Cancer Res
2019;25:967-76.

65. Sylvester RJ, Oosterlinck W, Holmang S, et al. Systematic Review and Individual Patient Data Meta-analysis of Randomized Trials Comparing a Single Immediate Instillation of Chemotherapy After Transurethral Resection with Transurethral Resection Alone in Patients with Stage pTa-pT1 Urothelial Carcinoma of the Bladder: Which Patients Benefit from the Instillation? Eur Urol 2016;69:231-44.

66. Sylvester RJ, Oosterlinck W, van der Meijden APM. A single immediate postoperative instillation of chemotherapy decreases the risk of recurrence in patients with stage Ta T1 bladder cancer: a meta-analysis of published results of randomized clinical trials. J Urol 2004;171:2186-90, quiz 2435.

67. Losa A, Hurle R, Lembo A. Low dose bacillus CalmetteGuerin for carcinoma in situ of the bladder: long-term results. J Urol 2000;163:68-71; discussion 71.

68. Takenaka A, Yamada Y, Miyake H, et al. Clinical outcomes of bacillus Calmette-Guérin instillation therapy for carcinoma in situ of urinary bladder. Int J Urol 2008;15:309-13.

69. Griffiths TRL, Charlton M, Neal DE, et al. Treatment of carcinoma in situ with intravesical bacillus CalmetteGuerin without maintenance. J Urol 2002;167:2408-12.

70. Gofrit ON, Pode D, Pizov G, et al. The natural history of bladder carcinoma in situ after initial response to bacillus Calmette-Gúerin immunotherapy. Urol Oncol 2009;27:258-62.

71. Jakse G, Hall R, Bono A, et al. Intravesical BCG in patients with carcinoma in situ of the urinary bladder: long-term results of EORTC GU Group phase II protocol 30861. Eur Urol 2001;40:144-50.

72. Stein JP, Lieskovsky G, Cote R, et al. Radical cystectomy in the treatment of invasive bladder cancer: long-term results in 1,054 patients. J Clin Oncol 2001;19:666-75.

73. International Collaboration of Trialists; Medical Research Council Advanced Bladder Cancer Working Party (now the National Cancer Research Institute Bladder Cancer Clinical Studies Group); European Organisation for Research and Treatment of Cancer Genito-Urinary Tract Cancer Group; International phase III trial assessing neoadjuvant cisplatin, methotrexate, and vinblastine chemotherapy for muscle-invasive bladder cancer: longterm results of the BA06 30894 trial. J Clin Oncol. J Clin Oncol 2011;29:2171-7.

74. Yin M, Joshi M, Meijer RP, et al. Neoadjuvant Chemotherapy for Muscle-Invasive Bladder Cancer: 
A Systematic Review and Two-Step Meta-Analysis.

Oncologist 2016;21:708-15.

75. Necchi A, Anichini A, Raggi D, et al. Pembrolizumab as Neoadjuvant Therapy Before Radical Cystectomy in Patients With Muscle-Invasive Urothelial Bladder Carcinoma (PURE-01): An Open-Label, Single-Arm, Phase II Study. J Clin Oncol 2018;36:3353-60.

76. Leow JJ, Martin-Doyle W, Rajagopal PS, et al. Adjuvant chemotherapy for invasive bladder cancer: a 2013 updated systematic review and meta-analysis of randomized trials. Eur Urol 2014;66:42-54.

77. Advanced Bladder Cancer (ABC) Meta-analysis Collaboration. Adjuvant chemotherapy in invasive bladder cancer: a systematic review and meta-analysis of individual patient data Advanced Bladder Cancer (ABC) Meta-analysis Collaboration. Eur Urol 2005;48:189-99; discussion 199.

78. Sternberg CN, Skoneczna I, Kerst JM, et al. Immediate versus deferred chemotherapy after radical cystectomy in patients with pT3-pT4 or N+M0 urothelial carcinoma of the bladder (EORTC 30994): an intergroup, open-label, randomised phase 3 trial. Lancet Oncol 2015;16:76-86.

79. Seisen T, Peyronnet B, Dominguez-Escrig JL, et al. Oncologic Outcomes of Kidney-sparing Surgery Versus Radical Nephroureterectomy for Upper Tract Urothelial Carcinoma: A Systematic Review by the EAU Non-muscle Invasive Bladder Cancer Guidelines Panel. Eur Urol 2016;70:1052-68.

80. Gallioli A, Boissier R, Territo A, et al. Adjuvant SingleDose Upper Urinary Tract Instillation of Mitomycin C After Therapeutic Ureteroscopy for Upper Tract Urothelial Carcinoma: A Single-Centre Prospective NonRandomized Trial. J Endourol 2020;34:573-80.

81. Giannarini G, Kessler TM, Birkhäuser FD, et al. Antegrade perfusion with bacillus Calmette-Guérin in patients with non-muscle-invasive urothelial carcinoma of the upper urinary tract: who may benefit? Eur Urol 2011;60:955-60.

82. Redrow GP, Guo CC, Brausi MA, et al. Upper urinary tract carcinoma in situ: current knowledge, future direction. J Urol 2017;197:287-95.

83. Foerster B, D'Andrea D, Abufaraj M, et al. Endocavitary treatment for upper tract urothelial carcinoma: A meta-analysis of the current literature. Urol Oncol 2019;37:430-6.

84. Margulis V, Shariat SF, Matin SF, et al. Outcomes of radical nephroureterectomy: a series from the Upper
Tract Urothelial Carcinoma Collaboration. Cancer 2009;115:1224-33.

85. Fang D, Seisen T, Yang K, et al. A systematic review and meta-analysis of oncological and renal function outcomes obtained after segmental ureterectomy versus radical nephroureterectomy for upper tract urothelial carcinoma. Eur J Surg Oncol 2016 Nov;42:1625-35.

86. Peyronnet B, Seisen T, Dominguez-Escrig JL, et al. Oncological outcomes of laparoscopic nephroureterectomy versus open radical nephroureterectomy for upper tract urothelial carcinoma: an european association of urology guidelines systematic review. Eur Urol Focus 2019;5:205-23.

87. Xylinas E, Kluth L, Passoni N, et al. Prediction of intravesical recurrence after radical nephroureterectomy: development of a clinical decision-making tool. Eur Urol 2014;65:650-8.

88. Fang D, Li XS, Xiong GY, et al. Prophylactic intravesical chemotherapy to prevent bladder tumors after nephroureterectomy for primary upper urinary tract urothelial carcinomas: a systematic review and metaanalysis. Urol Int 2013;91:291-6.

89. Meng X, Chao B, Vijay V, et al. High Response Rates to Neoadjuvant Chemotherapy in High-Grade Upper Tract Urothelial Carcinoma. Urology 2019;129:146-52.

90. Almassi N, Gao T, Lee B, et al. Impact of neoadjuvant chemotherapy on pathologic response in patients with upper tract urothelial carcinoma undergoing extirpative surgery. Clin Genitourin Cancer 2018;16:e1237-42.

91. Martini A, Daza J, Poltiyelova E, et al. Pathological downstaging as a novel endpoint for the development of neoadjuvant chemotherapy for upper tract urothelial carcinoma. BJU Int. 2019;124:665-71.

92. Liao RS, Gupta M, Schwen ZR, et al. Comparison of Pathological Stage in Patients Treated with and without Neoadjuvant Chemotherapy for High Risk Upper Tract Urothelial Carcinoma. J Urol 2018;200:68-73.

93. Birtle A, Johnson M, Chester J, et al. Adjuvant chemotherapy in upper tract urothelial carcinoma (the POUT trial): a phase 3, open-label, randomised controlled trial. Lancet 2020;395:1268-77.

94. McConkey DJ, Choi W, Shen Y, et al. A Prognostic Gene Expression Signature in the Molecular Classification of Chemotherapy-naïve Urothelial Cancer is Predictive of Clinical Outcomes from Neoadjuvant Chemotherapy: A Phase 2 Trial of Dosedense Methotrexate, Vinblastine, Doxorubicin, and Cisplatin with Bevacizumab in Urothelial Cancer. Eur 
Urol 2016;69:855-62.

95. Seiler R, Ashab HAD, Erho N, et al. Impact of Molecular Subtypes in Muscle-invasive Bladder Cancer on Predicting Response and Survival after Neoadjuvant Chemotherapy. Eur Urol 2017;72:544-54.

96. Rosenberg JE, Hoffman-Censits J, Powles T, et al. Atezolizumab in patients with locally advanced and metastatic urothelial carcinoma who have progressed following treatment with platinum-based chemotherapy: a single-arm, multicentre, phase 2 trial. Lancet 2016;387:1909-20.

97. Kim J, Kwiatkowski D, McConkey DJ, et al. The Cancer Genome Atlas Expression Subtypes Stratify Response to Checkpoint Inhibition in Advanced Urothelial Cancer

Cite this article as: Giudici N, Bonne F, Blarer J, Minoli M, Krentel F, Seiler R. Characteristics of upper urinary tract urothelial carcinoma in the context of bladder cancer: a narrative review. Transl Androl Urol 2021;10(10):4036-4050. doi: $10.21037 /$ tau-20-1472 and Identify a Subset of Patients with High Survival Probability. Eur Urol 2019;75:961-4.

98. Sharma P, Retz M, Siefker-Radtke A, et al. Nivolumab in metastatic urothelial carcinoma after platinum therapy (CheckMate 275): a multicentre, single-arm, phase 2 trial. Lancet Oncol 2017;18:312-22.

99. Powles T, Kockx M, Rodriguez-Vida A, et al. Clinical efficacy and biomarker analysis of neoadjuvant atezolizumab in operable urothelial carcinoma in the ABACUS trial. Nat Med 2019;25:1706-14.

100. Mariathasan S, Turley SJ, Nickles D, et al. TGF $\beta$ attenuates tumour response to PD-L1 blockade by contributing to exclusion of T cells. Nature 2018;554:544-8. 